\title{
Article \\ Effects of Pitch Size and Goalkeeper Participation on Physical Load Measures during Small-Sided Games in Sub-Elite Professional Soccer Players
}

\author{
Fernando J. Santos ${ }^{1,2,3}{ }^{\mathbb{D}}$, Carlos E. L. Verardi ${ }^{4,5}$, Mayra Grava de Moraes ${ }^{4,5}$, Dalton M. Pessôa Filho ${ }^{4,6}$, \\ Anderson G. Macedo ${ }^{4,5}$, Teresa P. Figueiredo ${ }^{2,3}$, Cátia C. Ferreira ${ }^{2,7}$, Ricardo P. Borba ${ }^{8}$ and Mário C. Espada $2,3, *$ (D) \\ 1 Faculty of Human Kinetics, University of Lisbon, 1499-002 Cruz Quebrada, Portugal; \\ fernando.santos@ese.ips.pt \\ 2 Polytechnic Institute of Setúbal, School of Education, 2914-504 Setúbal, Portugal; \\ teresa.figueiredo@ese.ips.pt (T.P.F.); catia.ferreira@ese.ips.pt (C.C.F.) \\ 3 Life Quality Research Centre, Complexo Andaluz, Apartado, 2040-413 Rio Maior, Portugal \\ 4 Department of Physical Education, São Paulo State University (UNESP), Bauru 17033-360, Brazil; \\ carlos.verardi@unesp.br (C.E.L.V.); mayra.grava@unesp.br (M.G.d.M.); \\ dalton.pessoa-filho@unesp.br (D.M.P.F.); andersongmacedo@yahoo.com.br (A.G.M.) \\ 5 Graduate Programme in Developmental Psychology and Learning, Faculty of Science, \\ São Paulo State University (UNESP), Bauru 17033-360, Brazil \\ Citation: Santos, F.J.; Verardi, C.E.L.; \\ de Moraes, M.G.; Filho, D.M.P.; \\ Macedo, A.G.; Figueiredo, T.P.; \\ 6 Graduate Programme in Human Development and Technology, São Paulo State University (UNESP), \\ Rio Claro 13506-900, Brazil \\ 7 Research Group in Optimization of Training and Sport Performance (GOERD), Faculty of Sports Sciences, \\ University of Extremadura, 10003 Caceres, Spain \\ 8 Mahd Sport Academy, Al Rafiah, Riyadh 12752, Saudi Arabia; rborba@mahdacademy.com \\ * Correspondence: mario.espada@ese.ips.pt; Tel.: +351-265-710-800
} Ferreira, C.C.; Borba, R.P.; Espada, M.C. Effects of Pitch Size and Goalkeeper Participation on Physical Load Measures during Small-Sided Games in Sub-Elite Professional Soccer Players. Appl. Sci. 2021, 11, 8024. https://doi.org/10.3390/ app11178024

Academic Editor: Shane Malone

Received: 15 July 2021

Accepted: 10 August 2021

Published: 30 August 2021

Publisher's Note: MDPI stays neutral with regard to jurisdictional claims in published maps and institutional affiliations.

Copyright: (c) 2021 by the authors. Licensee MDPI, Basel, Switzerland. This article is an open access article distributed under the terms and conditions of the Creative Commons Attribution (CC BY) license (https:/ / creativecommons.org/licenses/by/ $4.0 /)$.

\begin{abstract}
This study sought to examine the variations of internal and external load measures in soccer players when performing different types of 4 vs. 4 small-sided games (SSGs). Ten U-23 professional and sub-elite soccer players, eight outfield players (age: $20.1 \pm 1.5$ years old; height: $1.83 \pm 0.04 \mathrm{~m}$; total body mass: $76.1 \pm 3.6 \mathrm{~kg}$ ) and two goalkeepers (GK) (age: $20.5 \pm 2.1$ years old; height: $1.91 \pm 0.04 \mathrm{~m}$; total body mass: $77.0 \pm 1.4 \mathrm{~kg}$ ) participated in the study. Five SSGs were performed with 3 min duration and 3 min rest interval. SSG1, SSG2 and SSG4 aimed for ball possession play, while in SSG3 and SSG5, two GK were added, defending regular-size goals. The pitch size changed from SSG1 $(16 \times 24 \mathrm{~m})$ to SSG2 and SSG3 (both $20 \times 30 \mathrm{~m}$ ) and SSG4 and SSG5 (both $24 \times 36 \mathrm{~m}$ ). All players were monitored using WIMU Pro device during the tasks. Anova One-Way and the post hoc Tukey honestly significant difference were used for analysis of statistically significant differences $(p<0.05)$ and effect sizes were determined by calculating partial eta-squared. The framework was associated with relevant but steady state internal load fatigue and induce a considerable external load stimulus. GK participation in SSGs should be carefully considered as it seems to have a greater impact on physical load measures when compared to the pitch size manipulation.
\end{abstract}

Keywords: soccer; small-sided games; goalkeeper; pitch size; training load

\section{Introduction}

Today's sporting demands are higher than in the past, while the available time and conditions for training sessions are not always desirable for coaches, always looking for strategies to develop athletes' physical and tactical skills and improve the performance in the competitive moment. The management and monitoring of players' training load is vital to team success, especially in soccer, which is a high-intensity sport of intermittent bouts of activity, implying a substantial demand on the aerobic system [1]. Therefore, aerobic profiles are strongly related to performance-orientated outcomes [2]. 
Conventional endurance training, such as steady-state or extensive interval training, has traditionally been part of soccer coaches' aerobic training programs as it can enhance endurance capabilities [3]. Furthermore, athlete specific physical fitness, among which agility, speed or strength, have justified specific approaches and detailed analysis in scientific research [4]. Nevertheless, versions of the game may emerge from the interaction of different task manipulations and, if properly designed, new game forms may contribute to a higher and adjusted exertion level of the players [5]. Among these, the development of tactical and technical skills and, possibly, physiological/physical capacities [6], which are relevant since this sport requires an efficient collective organization and, simultaneously, specific development of each player, considering the individual and group framework/perspectives [7].

Small-sided games (SSGs) combine physical, technical, and tactical components, and have been recommended for performance enhancements [8]. Recently, the effects of SSGs were summarized across sixteen studies drawn from multiple sports and population types [5]. The authors concluded that SSGs were more effective for the development of skill and endurance than traditional conditioning or training. Even recreational soccer organized as SSG was recently indicated as an intense activity involving endurance, strength, aerobic, and anaerobic high-intensity interval training (HIIT) elements [9], highlighting the complexity of soccer dynamics expressed in collective and individual actions to be performed by the players [10].

SSGs are currently one of the most common practices used by coaches in their daily work, in order to develop technical and tactical skills, as well as the endurance capacity of their players [11]. The most common analyzed responses are physiological (heart rate, blood lactate), physical (distances, speeds, time), perceptual and technical [12]. Although the most examined variables are the pitch size, player number and the multiple combinations of them [13], other aspects have received attention in research such as inclusion of goalkeepers (GK) [14]. However, the shortage of studies using different intermittent regimens of SSGs and its consequences on training load [15,16] do not provide coaches with clear guidelines to understand the real impact of different regimens, in terms of the overall stimulus per set and the possible drop in performance throughout the task.

With regard to the types of scoring in SSGs, it was previously found that the stop-ball SSG (in a $1 \mathrm{~m}$ wide zone behind the end line) induced higher heart rate (HR) values than the small-goal SSG (score in small goals placed at the center of the end line) when using three pitch dimensions $(10 \times 15 \mathrm{~m}, 15 \times 20 \mathrm{~m}$, and $20 \times 25 \mathrm{~m})$ and within three game formats ( 2 vs. $2 ; 3$ vs. 3 and 4 vs. 4 players) $[17,18]$. Although smaller game formats seem to promote a higher exercise intensity and number of decelerations actions in professional soccer players [19], it was reported that both 4 vs. 4 SSGs and 15sec-15sec HIIT sessions induced similar physiological responses. However, HIIT produced a mood disturbance, while SSG ensured mood balance [20].

Furthermore, the majority of SSGs studies were conducted with youth or non- professional soccer players. Studies conducted at a professional and elite or sub-elite level are scarce, largely due to a high-density weekly training schedule, regular trips/journeys between competitions and throughout the season to a high-density competitive calendar. Nevertheless, it is very important to study the internal and external training load of SSGs at this competitive level, aiming to improve the training prescription, but also the understanding of specificity of the response on different training formats and SSGs conditions. Considering these reasons, the purpose of this study was to evaluate the variations of internal and external load between different SSGs 4 vs. 4 formats in professional and sub-elite under-23 (U-23) soccer players.

\section{Materials and Methods}

\subsection{Participants}

Ten professional and sub-elite soccer players from the same team, eight outfield players (age: $20.1 \pm 1.5$ years old; height: $1.83 \pm 0.04 \mathrm{~m}$; total body mass: $76.1 \pm 3.6 \mathrm{~kg}$; body 
fat: $10.1 \pm 2.2 \%$ and experience: $13.3 \pm 1.5$ years) and two GK (age: $20.5 \pm 2.1$ years old; height: $1.91 \pm 0.04 \mathrm{~m}$; total body mass: $77.0 \pm 1.4 \mathrm{~kg}$; body fat: $9.7 \pm 1.2 \%$ and experience: $13.5 \pm 0.7$ years) participated in the study. All players integrated a Portuguese soccer club with honors and credits at both national and international levels, evident by the number of youth players selected to the national teams over the years. Subjects were members of the U-23 club squad, playing in the national league, which provides a highly competitive environment and a pathway for players to reach the first team and national teams. It is important to point out that most of the participants in this study were national team players for their respective countries in this age group. On average, the players practiced 10-11 months per year with 5-6 weekly training sessions plus one match per week by the time of the data collection (in some periods of the competitive calendar, participants had two matches per week). The majority of the players trained regularly with the club first team based on temporary requests but also from a learning experience perspective. The inclusion criteria for the players participating in the SSGs were: (1) players without injuries in the last two months; (2) players participation in all training sessions in the last six weeks prior to data collection; and (3) players participation in the total playing time in the last month of competition prior to data collection. Our study was conducted in accordance with the international ethical standards for sport and exercise science research [21] and in accordance with the Declaration of Helsinki. This study was submitted to the Ethical Committee of São Paulo State University (UNESP), which was registered and approved under (CAAE: 02523412.4.0000.5398, final report $\mathrm{n}^{\mathrm{o}}$ : 237.707). Informed consents were obtained from soccer players participating in the study.

\subsection{Study Design}

Five SSGs were performed with different conditions. The research was conducted near the end of the 2018-2019 competitive season. The training session took place in May, started at 10:00 and lasted approximately $1 \mathrm{~h}$. The tasks were performed on natural grass floor (in very good condition). Twenty-four hours prior to the experimental session, the players were instructed to maintain their usual habits, which included $8 \mathrm{~h}$ of sleep the night before the data collection session and to maintain the nutritional routine. The training session started with a 25 min standardized warm-up, consisting of 5 min of slow jogging, and strolling locomotion followed by 12 min of specific soccer drills and finishing with $3 \mathrm{~min}$ of progressive sprints and accelerations. Agility and speed drills were also conducted and 5 min of a ball possession game within a space of $20 \times 20 \mathrm{~m}$ concluded the warm-up.

Players were randomly assigned to the playing teams, with no specific tactical missions. Game format was characterized as possession play (SSG-P, specifically SSG1, SSG2 and SSG4) and game with regular goals and GK participation (SSG-G, specifically, SSG3 and SSG5). Since communication is a relevant element in the coach-athlete relationship [22], during all the SSGs, coaches provided some feedback aiming to encourage the players. Colleagues and coaches were around the pitch with soccer balls in their hands to quickly replace the ball every time it left the pitch size during all the SSGs. Throughout the recovery time periods in the SSGs, players could rehydrate. Table 1 presents the SSGs' conditions.

Table 1. Small-sided games performed with different conditions.

\begin{tabular}{ccccc}
\hline Tasks & Format & Space $(\mathbf{m})$ & Duration (min) & Pause (min) \\
\hline SSG1 (SSG-P) & 4 vs. 4 & $16 \times 24$ & 3 & 3 \\
SSG2 (SSG-P) & 4 vs. 4 & $20 \times 30$ & 3 & 3 \\
SSG3 (SSG-G) & GK + 4 vs. $4+$ GK & $20 \times 30$ & 3 & 3 \\
SSG4 (SSG-P) & 4 vs. 4 & $24 \times 36$ & 3 & 3 \\
SSG5 (SSG-G) & GK + 4 vs. $4+$ GK & $24 \times 36$ & 3 & 3 \\
\hline
\end{tabular}

In SSG1, SSG2 and SSG4, the objective of the game was for the team to keep the ball in their possession for as long as possible. On the other hand, in SSG3 and SSG5, the main objective of the game was to score more goals than the opposing team. An SSG in $16 \times 24 \mathrm{~m}$ with GK participation was not planned because SSG1 and SSG2 would take place in a phase close to the warm-up, and an SSG in this pitch dimension with goal objective in 
regular-size goals defended by GK leads to players making several shots aiming to score, which could increase the risk of injury. Figure 1 displays the performed SSGs.

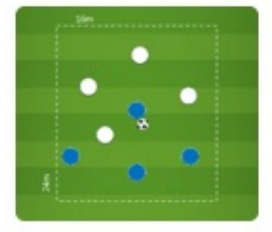

SSG 1

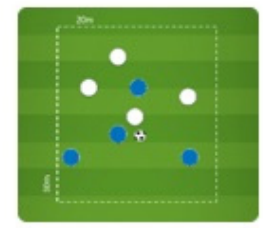

SSG 2

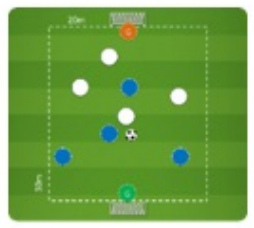

SSG 3

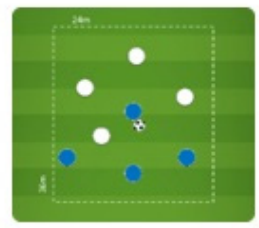

SSG 4

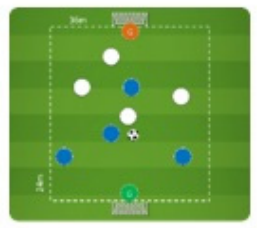

SSG 5

Figure 1. Illustrative scheme of the small-sided games. Blue and white dots represent outfield players, the position in the pitch is solely an example, red and green dots represent the goalkeepers.

\subsection{Procedures}

Soccer players carried global positioning system (GPS) devices (WIMU PRO ${ }^{\mathrm{TM}}$, RealTrack System, Almería, Spain) operating at a sampling frequency of $10 \mathrm{~Hz}$. The technology used to collect the GPS data had been previously validated and was shown to be reliable for monitoring soccer players [23]. Participants wore a fitted body vest, and the GPS device was inserted in a purpose-built harness prior to the SSGs. Before being placed on the players, the GPS devices were calibrated and synchronized following the manufacturer's recommendations. The procedure was as follows: (a) turn on the devices, (b) wait approximately $30 \mathrm{~s}$ after turning them on, (c) press the button to start recording once the device's operating system is initialized and (d) analyze the data obtained from the devices using SPRO ${ }^{\mathrm{TM}}$ software (RealTrack Systems, Almería, Spain). SPRO ${ }^{\mathrm{TM}}$ software calculates the external load indicator used in our study. Player load is derived from triaxial accelerometers $(x, y$ and $z)$, which are used to evaluate neuromuscular load in different athletes.

$$
\begin{gathered}
P L_{n}=\sqrt{\frac{\left(x_{n}-x_{n-1}\right)^{2}+\left(y_{n}-y_{n-1}\right)^{2}+\left(z_{n}-z_{n-1}\right)^{2}}{100}} \\
\text { Accumulated } P L=\sum_{n=0}^{m} P L_{n} \times 0.01
\end{gathered}
$$

\subsection{Statistical Analysis}

All the results are related with the outfield game players (total 8, 4 vs. 4 in all the played SSGs). GK were not evaluated for the purpose of this study because they did not participate in the same and regular physical training program of the outfield. The internal and external load variables were characterized using descriptive analysis (mean and standard deviation). The normality of the distributions was assessed with the Shapiro-Wilk test. Parametric and nonparametric statistics were selected accordingly. We verified with Anova One-Way and the post hoc Tukey honestly significant difference (HSD) analysis the existence of statistically significant differences. Significance level was set at $p<0.05$. Effect sizes were determined by calculating partial eta-squared [24]. Effect sizes are considered as small $\left(\eta_{\rho}^{2}<0.06\right)$, moderate $\left(0.06>\eta_{\rho}^{2}<0.15\right)$ or large $\left(\eta_{\rho}^{2} \geq 0.15\right)$ [25]. The data analysis was carried out using the Statistical Package for Social Sciences (SPSS 25.0, SPSS. Inc., Chicago, IL, USA).

\section{Results}

The area of game per player, as well as the players performance in all played SSGs regarding the total distance covered, maximum and mean $\mathrm{HR}\left(\mathrm{HR}_{\max }\right.$ and $\left.\mathrm{HR}_{\text {mean }}\right)$ and player load volume and intensity are depicted in Table 2. 
Table 2. Variations between internal and external load variables in different areas of game per player.

\begin{tabular}{|c|c|c|c|c|c|c|}
\hline SSGs & $\begin{array}{c}\text { Area of Game Per } \\
\text { Player }\left(\mathrm{m}^{2}\right)\end{array}$ & $\begin{array}{l}\text { Total Distance } \\
\text { Covered (m) }\end{array}$ & $\begin{array}{l}\text { Max. Heart Rate } \\
\text { (bpm) }\end{array}$ & $\begin{array}{l}\text { Mean Heart } \\
\text { Rate (bpm) }\end{array}$ & $\begin{array}{l}\text { Player Load } \\
\text { (Volume) }\end{array}$ & $\begin{array}{c}\text { Player } \\
\text { Load } \\
\text { (Intensity) }\end{array}$ \\
\hline SSG1 & 48 & $369.4 \pm 19.9$ & $184.9 \pm 5.3$ & $169.9 \pm 9.4$ & $6.3 \pm 0.4$ & $2.0 \pm 0.1$ \\
\hline SSG2 & 75 & $384.4 \pm 28.2$ & $189.1 \pm 3.0$ & $176.7 \pm 4.5$ & $6.4 \pm 0.7$ & $2.1 \pm 0.2$ \\
\hline SSG3 & 60 & $322.7 \pm 25.1$ & $187.6 \pm 4.4$ & $174.9 \pm 6.0$ & $5.4 \pm 0.3$ & $1.7 \pm 0.2$ \\
\hline SSG4 & 108 & $410.8 \pm 34.6$ & $188.6 \pm 4.9$ & $176.9 \pm 7.1$ & $6.7 \pm 0.8$ & $2.0 \pm 0.2$ \\
\hline SSG5 & 86 & $350.2 \pm 29.4$ & $186.1 \pm 4.7$ & $175.6 \pm 6.3$ & $5.4 \pm 0.4$ & $1.7 \pm 0.2$ \\
\hline$F$ & - & 9.131 & 0.967 & 1.134 & 7.130 & 4.449 \\
\hline$P$ & - & $0.000 * *$ & 0.440 & 0.359 & $0.000 *$ & $0.006^{*}$ \\
\hline$\eta_{\rho}^{2}$ & - & 0.549 & 0.114 & 0.131 & 0.487 & 0.373 \\
\hline Tukey HSD & - & $\begin{array}{r}1 * 3(0.04) ; 2 * 3(0.04) \\
3 * 4(0.00) ; 4 * 5(0.00)\end{array}$ & & & $\begin{array}{l}2 * 3(0.02) \\
2 * 5(0.02) \\
3 * 4(0.04) ; \\
4 * 5(0.02)\end{array}$ & $\begin{array}{l}2 * 3(0.04) \\
2 * 5(0.04)\end{array}$ \\
\hline
\end{tabular}

SSG1: 4 vs. $4,16 \times 24$ m; SSG2: 4 vs. 4, $20 \times 30$ m; SSG3: GK + 4 vs. 4 + GK, $20 \times 30$ m; SSG4: 4 vs. 4 , $24 \times 36$ m; SSG5: GK + 4 vs. 4 + GK, $24 \times 36 \mathrm{~m}$. All SSGs with $3 \mathrm{~min}$ duration and $3 \mathrm{~min}$ rest (ratio 1:1). Bpm represents beats per minute; Player load volume and intensity associated with arbitrary unit (a.u.). ${ }^{*}$ Significant differences between SSGs $(p<0.01)$; ${ }^{*}$ Significant differences between SSGs $(p<0.05)$.

The distance covered concomitantly increased with the increase in pitch size $($ SSG-P $=16 \times 24 \mathrm{~m}=369.4 \pm 19.9 \mathrm{~m} ; 20 \times 30 \mathrm{~m}=384.4 \pm 28.2 \mathrm{~m} ; 24 \times 36 \mathrm{~m}=410.8$ $\pm 34.6 \mathrm{~m} / \mathrm{SSG}-\mathrm{G}=16 \times 24 \mathrm{~m}=322.7 \pm 25.1 \mathrm{~m} ; 24 \times 36 \mathrm{~m}=350.2 \pm 29.4 \mathrm{~m})$, but significant statistical differences were only observed when one of the played SSG involved the GK participation. It was also clear that playing with the GK resulted in lower distances covered by the outfield players (SSG3 $<$ SSG2; $p<0.05 /$ SSG5 $<$ SSG4; $p<0.01$ ). No significant differences were observed throughout the SSGs in $\mathrm{HR}_{\max }$ and $\mathrm{HR}_{\text {mean. Nevertheless, in }}$ $\mathrm{HR}_{\max }$ and $\mathrm{HR}_{\text {mean, }}$, the lower mean value was always observed in the first performed SSGs (with the smaller area of game per player $16 \times 24 \mathrm{~m}$ ). It was also observed that GK participation resulted in the decrease in both $\mathrm{HR}_{\max }$ and $\mathrm{HR}_{\text {mean }}$ comparatively to the same pitch size but SSG-P, without goal objective. The lower values of PL volume and intensity were observed in SSG3 and SSG5, the only two SSGs with GK participation. The transition from SSG1 to SSG2 promoted the increase in PL volume and intensity, but without significant differences, contrary to the decrease in PL volume between SSG2 and SSG3 and also between SSG4 and SSG5 (in both cases $p<0.05$ ). When analyzing PL intensity, SSG3 mean value was significantly lower compared to SSG2 $(p<0.05)$, and despite the decrease from SSG4 to SSG5, the difference was not significant. Table 3 presents the results related to the HR zones in different forms of SSGs.

Table 3. Heart rate percentage in different forms of small-sided games.

\begin{tabular}{|c|c|c|c|c|c|c|}
\hline \multirow[t]{3}{*}{ SSGs } & \multicolumn{6}{|c|}{ Relative Heart Rate (\%) } \\
\hline & $(50 ; 60)$ & $(60 ; 70)$ & $(70 ; 80)$ & $(80 ; 90)$ & $(90 ; 95)$ & $(>95)$ \\
\hline & Very Low & Low & Moderate & High & Very High & Max. \\
\hline SSG1 & $6.3 \pm 4.8$ & $6.0 \pm 5.8$ & $7.3 \pm 4.7$ & $49.0 \pm 27.7$ & $28.5 \pm 30.0$ & $2.8 \pm 7.5$ \\
\hline SSG2 & $0.8 \pm 2.1$ & $8.4 \pm 4.8$ & $7.6 \pm 3.1$ & $20.8 \pm 10.7$ & $54.1 \pm 10.7$ & $8.3 \pm 14.2$ \\
\hline SSG3 & $1.6 \pm 3.0$ & $6.0 \pm 2.9$ & $10.3 \pm 6.8$ & $34.6 \pm 18.6$ & $39.8 \pm 19.8$ & $7.8 \pm 13.0$ \\
\hline SSG4 & $1.6 \pm 2.3$ & $3.4 \pm 2.9$ & $6.0 \pm 2.3$ & $34.5 \pm 26.4$ & $47.0 \pm 25.2$ & $7.5 \pm 9.2$ \\
\hline SSG5 & 0 & $1.9 \pm 3.8$ & $8.3 \pm 4.9$ & $50.0 \pm 30.7$ & $37.9 \pm 32.7$ & $1.6 \pm 4.0$ \\
\hline$F$ & 4.738 & 2.370 & 0.734 & 1.637 & 0.968 & 0.590 \\
\hline$P$ & $0.004^{* *}$ & 0.075 & 0.574 & 0.191 & 0.440 & 0.672 \\
\hline
\end{tabular}

SSG1: 4 vs. $4,16 \times 24 \mathrm{~m}$; SSG2: 4 vs. $4,20 \times 30$ m; SSG3: GK + 4 vs. 4 + GK, $20 \times 30$ m; SSG4: 4 vs. 4 $24 \times 36 \mathrm{~m}$; SSG5: GK +4 vs. $4+\mathrm{GK}, 24 \times 36 \mathrm{~m}$. All SSGs with 3 min duration and 3 min rest (ratio 1:1). ** Significant differences between SSGs $(p<0.01)$.

In the SSGs-P, the increase in pitch dimensions (from $16 \times 24 \mathrm{~m}$ to $20 \times 30 \mathrm{~m}$; SSG1 to SSG2) resulted in significant differences in very low $\mathrm{HR}_{50 ; 60}$. No significant differences were observed with the inclusion of GK considering the same pitch size (SSG2 to SSG3 and SSG4 to SSG5). It should be highlighted that in SSG5, the last to be performed, very low $\mathrm{HR}_{50-60}$ was not observed in the outfield players. In $\mathrm{HR}_{60 ; 70}$ and $\mathrm{HR}_{>} 95$ the $\mathrm{HR}$ percentage values 
decreased from SSG2 to SSG5. In moderate, high, and very high HR no linear tendency or significant differences were observed between the different SSGs. Nevertheless, the higher mean values of $\mathrm{HR}$ percentage were observed in $\mathrm{HR}_{80 ; 90}$ and $\mathrm{HR}_{90 ; 95}$, in all cases above $20 \%$, contrary to very low, low, moderate and $\mathrm{HR}_{>95}$, where the highest mean value was $10.3 \%$. Table 4 presents the players speed in all the performed SSGs.

Table 4. Soccer players distance covered at different interval speeds in all the performed small-sided games.

\begin{tabular}{|c|c|c|c|c|c|c|}
\hline SSGs & $\begin{array}{l}\text { Absolute } \\
\text { Speed 0-6 } \\
(\mathrm{m} / \mathrm{min})\end{array}$ & $\begin{array}{c}\text { Absolute } \\
\text { Speed 6-12 } \\
\text { (m/min) }\end{array}$ & $\begin{array}{c}\text { Absolute } \\
\text { Speed 12-18 } \\
\text { (m/min) }\end{array}$ & $\begin{array}{l}\text { Absolute } \\
\text { Speed 18-21 } \\
\text { (m/min) }\end{array}$ & $\begin{array}{c}\text { Absolute } \\
\text { Speed 21-24 } \\
\text { (m/min) }\end{array}$ & $\begin{array}{c}\text { Absolute } \\
\text { Speed 24-50 } \\
\text { (m/min) }\end{array}$ \\
\hline SSG1 & $104.7 \pm 14.2$ & $196.9 \pm 29.2$ & $65.4 \pm 15.6$ & $2.4 \pm 2.5$ & 0 & 0 \\
\hline SSG2 & $81.9 \pm 29.2$ & $205.9 \pm 21.8$ & $85.8 \pm 28.9$ & $2.3 \pm 3.4$ & 0 & 0 \\
\hline SSG3 & $114.3 \pm 13.2$ & $151.0 \pm 32.8$ & $40.7 \pm 27.2$ & $3.7 \pm 2.5$ & $1.2 \pm 1.9$ & 0 \\
\hline SSG4 & $82.40 \pm 36.0$ & $199.5 \pm 31.5$ & $96.3 \pm 26.7$ & $11.7 \pm 11.2$ & $6.4 \pm 7.7$ & $0.9 \pm 1.6$ \\
\hline SSG5 & $109.7 \pm 14.7$ & $91.7 \pm 40.2$ & $14.1 \pm 8.0$ & $4.0 \pm 5.5$ & $0.2 \pm 0.5$ & 0 \\
\hline$F$ & 2.734 & 14.861 & 13.926 & 2.639 & 3.676 & 2.236 \\
\hline$P$ & 0.047 * & 0.000 * & 0.000 * & 0.053 & 0.015 * & 0.089 \\
\hline$\eta_{\rho}^{2}$ & 0.267 & 0.665 & 0.650 & 0.260 & 0.329 & 0.230 \\
\hline Tukey HSD & & $\begin{array}{l}1 * 5(0.00) \\
2 * 3(0.03) \\
2 * * 5(0.00) \\
3 * 5(0.02) \\
4 * 5(0.00)\end{array}$ & $\begin{array}{l}1 * 5(0.03) ; \\
2 * * 1(0.01) ; \\
2 * * 5(0.00) ; \\
3 * * 2(0.01) ; \\
3 * * 4(0.00) ; \\
4 * * 5(0.00)\end{array}$ & & $\begin{array}{l}1 * 4(0.03) ; \\
2 * 4(0.03) ; \\
4 * 5(0.04)\end{array}$ & \\
\hline
\end{tabular}

SSG1: 4 vs. $4,16 \times 24$ m; SSG2: 4 vs. $4,20 \times 30$ m; SSG3: GK + 4 vs. 4 + GK, $20 \times 30$ m; SSG4: 4 vs. $4,24 \times 36$ m; SSG5: GK + 4 vs. 4 + GK, $24 \times 36 \mathrm{~m}$. All SSGs with $3 \mathrm{~min}$ duration and $3 \mathrm{~min}$ rest (ratio 1:1). ${ }^{* *}$ Significant differences between SSGs $(p<0.01) ;{ }^{*}$ Significant differences between SSGs $(p<0.05)$.

Several significant differences were observed in speed intervals. In the higher speeds $\left(24-50 \mathrm{~km} \cdot \mathrm{h}^{-1}\right)$, small or null mean values of distance covered were observed. The same was observed in $21-24 \mathrm{~km} \cdot \mathrm{h}^{-1}$ speed, with only some minor mean values of distance covered in SSG4 (the higher in SSG-P played in $24 \times 36 \mathrm{~m}, 6.4 \pm 7.7 \mathrm{~m} / \mathrm{min}$ ), significantly higher compared to SSG1, SSG2 (all SSGs-P with lower pitch size) and SSG5 $(p<0.05)$. In $18-21 \mathrm{~km} \cdot \mathrm{h}^{-1}$, the highest mean values of distance covered at this speed were also verified in SSG4 but considering all the played SSGs the values were small.

We have noticed that the distance covered by the sub-elite soccer players occurred predominantly at $0-6,6-12$ and $12-18 \mathrm{~km} \cdot \mathrm{h}^{-1}$ speed. The distance covered at $12-18 \mathrm{~km} \cdot \mathrm{h}^{-1}$ always increased in SSGs-P with pitch size increase, contrary to the transition between SSGs with the same pitch size but GK participation and goal objective, where values always significantly decreased (SSG5 $<$ SSG4 and SSG3 $<$ SSG2; $p<0.01$ in both cases). The higher mean values of distance covered were observed at $6-12 \mathrm{~km} \cdot \mathrm{h}^{-1}$, and as noted in $12-18 \mathrm{~km} \cdot \mathrm{h}^{-1}$, always decreased in the transition between SSG-P and SSG-G, but with very close mean values in between SSGs-P (SSG1, SSG2 and SSG4), despite the increase in pitch size. The distance covered at $0-6 \mathrm{~km} \cdot \mathrm{h}^{-1}$ presents close mean values, decreasing from SSG1 to SSG2 and, contrary to the speed above, also increased between SSG-P and SSG-G with the same pitch size (SSG3 > SSG2 and SSG5 > SSG4). It is of note that the distance covered always decreased throughout the sequence of SSG1, SSG2, SSG3 and SSG4 considering the increase in running speed between $6 \mathrm{~km} \cdot \mathrm{h}^{-1}$ and $24-50 \mathrm{~km} \cdot \mathrm{h}^{-1}$ but in SSG5, this evidence was observed from $0 \mathrm{~km} \cdot \mathrm{h}^{-1}$ up to $24-50 \mathrm{~km} \cdot \mathrm{h}^{-1}$. A common trend was observed regarding distance covered at different running speeds, always increased in running speed intervals between 6 and $50 \mathrm{~km} \cdot \mathrm{h}^{-1}$ between SSG3 and SSG4, decreasing afterwards from SSG4 to SSG5, but this trend was only not observed in $0-6 \mathrm{~km} \cdot \mathrm{h}^{-1}$ running speed.

\section{Discussion}

The purpose of this study was to evaluate the variations of internal and external load between different forms of SSGs in professional and sub-elite U-23 soccer players. 
This is one of the few studies conducted with international level players since these are exposed to intense training and weighty competitive density. The major findings associated with 5 SSGs performed with 3 min play and 3 min interval rest were: (i) Total distance covered increases in SSGs-P played between $16 \mathrm{~m}$ and $36 \mathrm{~m}$ but always decreases with GK participation in different SSG but with the same pitch size; (ii) $\mathrm{HR}_{\max }$ and $\mathrm{HR}_{\text {mean }}$ decrease with GK participation but present steady state mean values throughout the SSG framework; (iii) PL volume and intensity decreases and has the lowest values with GK participation, namely in SSG3 and SSG5; (iv) The relative HR percentage in this soccer training task is predominantly high $(80 ; 90 \%)$ and very high $(90 ; 95 \%)$, mean values increasing in moderate and high relative HR with GK participation, contrarily to the decrease in very high and max relative HR; (v) The five performed SSGs were predominantly associated with distances covered at $0-6,6-12$ and $12-18 \mathrm{~km} \cdot \mathrm{h}^{-1}$ running speeds with distance covered tendentially decreasing in every running speed interval with GK participation (exception $0.6 \mathrm{~km} \cdot \mathrm{h}^{-1}$ ) and globally the lower values in each running speed occurred in SSG5 (also with the exception of $0.6 \mathrm{~km} \cdot \mathrm{h}^{-1}$ ) and (vi) The performance of five consecutive SSGs with $3 \mathrm{~min}$ play and $3 \mathrm{~min}$ rest interval with increasing pitch size $(16 \times 24 \mathrm{~m} \mathrm{SSG1}$ and SSG2; $20 \times 30 \mathrm{~m}$ SSG3 and SSG4 and $24 \times 36 \mathrm{~m}$ SSG5) and SSG1, SSG2 and SSG4 characterized has ball possession game and SSG3 and SSG5 with goal objective and GK participation, promote different internal and external load responses in sub-elite U-23 soccer players which should be carefully monitored during daily training.

Previous research used the 5 vs. 5 plus GK format as a setting for assessing the physical and physiological demands in ten young soccer players in four repetitions of $6 \mathrm{~min}$ in a space of $100 \mathrm{~m}$ (SSG1) or $200 \mathrm{~m}$ (SSG2) and six repetitions of $4 \mathrm{~min}$ in $100 \mathrm{~m}$ (SSG3) or $200 \mathrm{~m}$ (SSG4), the authors suggested increasing pitch size to induce greater physical demands and to use SSGs with smaller pitch size, and independently of the bout duration, to induce neuromuscular fatigue [26]. Additionally, another study conducted with young Italian soccer players, compared the effects of different types of SSGs (3 vs. 3, 4 vs. 4 , and 5 vs. 5) with aerobic interval training. Apart from the time spent above $95 \% \mathrm{HR}_{\max }$, the results showed no differences in terms of intensity [27]. Differences in HR response between game formats have also been found in a few studies on amateur [28] and professional elite soccer players [29] and in general, HR increases with increasing area per player [11]. Additionally, the 3 vs. 3 format was previously tested in three regimens and found that long sets $(3 \times 6 \mathrm{~min} / 2 \mathrm{~min}$ rest) contributed to a drop in HR responses compared to medium $(3 \times 4 \mathrm{~min} / 2 \mathrm{~min}$ rest $)$ and short sets $(3 \times 2 \mathrm{~min} / 2 \mathrm{~min}$ rest $)$, although, no significant difference was observed for perceived effort or technical actions [15]. More recently, it was observed in recreationally active male soccer players that $\mathrm{HR}$ was above $90 \% \mathrm{HR}_{\max }$ in $45 \%$ of the total playing time $\left(2 \times 20 \mathrm{~min}\right.$ SSG with, respectively, 80 and $60 \mathrm{~m}^{2}$ per player) [30].

In our study, $\mathrm{HR}_{\max }$ and $\mathrm{HR}_{\text {mean }}$ presented no significant differences in the outfield players when all the five played SSGs were compared, the lower mean values were always observed in the first SSG (pitch size $16 \times 24 \mathrm{~m}$ ) and both $\mathrm{HR}_{\max }$ and $\mathrm{HR}_{\text {mean }}$ always increased comparing SSGs with the same pitch area but different objective (SSG-P or SSG-G). When analyzing the relative HR, we could observe that the SSG training framework of this study is physiological demanding, since the majority of HR\% was high $(80 ; 90 \%)$ and very high $(90 ; 95 \%)$ and in very high and maximal $\mathrm{HR} \%$ the mean values even decreased between SSG4 and SSG5. Another interesting finding was that in moderate and high HR\% the GK participation in SSGs was associated with an increase in mean values, contrary to what occurred in very high and maximal $\mathrm{HR} \%$. This evidence revealed that five SSGs with professional and sub-elite soccer players composed by 3 min performance and $3 \mathrm{~min}$ rest interval is a task that is very relevant from the physiological perspective, but can be accomplished with internal load steady state, aiming to develop the aerobic pathway. Notably, in the lower HR zone percentages, the HR mean values tended to decrease or stabilize from SSG1 to SSG5, which reveals a physiological adaptation to the tasks, a condition that we attribute to the level of the soccer players, who are familiar with daily routines of intense training and competition in a very demanding level. 
Previous studies showed that rule modifications could influence physical responses during SSGs. For example, Köklü et al. [31] examined the physical responses of youth players in three different SSG formats (2-a-side, 4-a-side, and 6-a-side) with a constant pitch area and reported that SSGs rule modifications can affect physical responses. Additionally, comparing the internal and external load variations between training regimens it was observed that shorter sets elicited a lower $\mathrm{HR}_{\max }$, a shorter distance covered at low running speed and contributed to an increase in the distances covered at both medium and high speeds running. Additionally, a study was developed with elite soccer players (English Premier League and UEFA Champions League level players), with different formats (SSG-P and SSG-G), the same number of outfield soccer players (5 vs. $5 / 7$ vs. $7 / 10$ vs. 10 ) and different pitch sizes (SSG-G 5 vs. $5=30 \times 30 \mathrm{~m} / 7$ vs. $7=45 \times 35 \mathrm{~m} / 10$ vs. $1066 \times 45 \mathrm{~m}$ and SSG-P 5 vs. $5=27 \times 27 \mathrm{~m} / 7$ vs. $7=37 \times 37 \mathrm{~m} / 10$ vs. $1052 \times 52 \mathrm{~m}$ ), each drill by this sequence in a continuous regime and all variables were normalized by time (4 min) for data analysis [32]. The main findings of this research were that the total distance, distances run at high speed as well as absolute maximum velocity, accelerations and decelerations increased with large pitch dimensions ( 10 vs. $10>7$ vs. $7>5$ vs. 5 ). Furthermore, the total distance, very high and maximal speed distances, absolute velocity and absolute maximum acceleration and deceleration were higher in SSG-G compared to SSG-P. The authors explained their results by an increase in linear behaviors in games with a defined offensive side (GK conditions).

In our study, total distance covered concomitantly increased with the rise in pitch size independent of the condition (SSG-P or SSG-G), but significant statistical differences were only observed in SSGs with GK participation, the distance covered in SSGs-G was significantly lower compared to the same pitch dimension SSG-P. Comparing our results with Gaudino et al. [32] we can speculate that the participation of GK and goal objective is a main factor for significant differences in the performance of soccer players during SSGs. This is supported in our study by the decreasing values in distance covered, $\mathrm{HR}_{\max }$, $\mathrm{HR}_{\text {mean }}$, speed 6-12 and 12-18, PL volume and intensity between the SSGs with the same pitch size, but different condition (ball possession or goal), findings that highlight that manipulating the pitch size by itself may not be the best strategy for soccer coaches aiming to modulate the exercise intensity. Regarding this topic, previous comparison between 4 vs. 4 and 6 vs. 6 SSG formats suggested that exercise intensity decreases as the pitch size increases, and a similar suggestion has resulted from a comparison between 7 vs. 7 and 10 vs. 10 SSG formats [33]. Additionally, PL values observed in this study, which are associated with the intensity of the game (namely accelerations and decelerations), supported the suggestion that smaller formats seem better for increasing exercise intensity and the number of accelerations and decelerations by soccer players [19], nonetheless, the use of GK and goal objective seems to be a good strategy if the purpose is to decrease the intensity during the SSG since often in SSGs these factors are not associated with the necessity of very intense actions such as changes in direction, sprints, accelerations and decelerations.

Furthermore, it has been suggested in the literature that fatigue mechanisms affect decision-making skills [34] and the higher physiological strain typically observed in SSGs on larger pitches is likely to be due to the possibility of making longer offensive and defensive runs [35]. This methodology could add to a congested training schedule, causing excessive physical stress which, in turn, can result in burnout and/or injury in players [36]. Addressing this topic, Clemente et al. [37] stressed that the $3 \mathrm{vs.} 3$ format is perhaps less structured than the 6 vs. 6 format in terms of the tactical approach to the match, allowing each player to assume more than only one role (e.g., defender or attacker) and to participate in all moments of the match. This indication was in line with previous findings that revealed a tendency of players to be more conservative in the 6 vs. 6 and aggressive in the 3 vs. 3 format, probably based on the space management and the fewer interactions between teammates [38]. In a comparative study of two intermittent regimens (4 vs. $4 \mathrm{~min}$ and $2 \mathrm{vs} .8 \mathrm{~min}$ ), it was found that both the first four-minute periods of exertion had greater 
values of total distance [39], thus suggesting that the time of recovery was not enough to enable players to achieve similar levels as they did in the absence of fatigue. In the 4 vs. 4 format tested by Dellal et al. [40] a progressive decrease in total distance was found from the first to the fourth set $4 \times 4$ min with 3 min passive recovery, $30 \times 20 \mathrm{~m}$, SSG-P with the help of four support players-out of the playing area and not allowed to perform more than 1 touch for each involvement), and was justified by the possible accumulation of potassium in the muscle interstitium and the subsequent depolarization of the muscle membrane potential, which reduced the force development during these intensity drills [3].

Our results indicate that in sub-elite U-23 soccer players, the 3 min exercise with 3 min time recovery provides the possibility of balance in fatigue throughout the SSGs, since contrary to the study of Dellal et al. [40], also with international soccer players, in our study, the distance covered always increased from SSG1 to SSG4, except when involving GK participation. We should, however, underline that based on our study results and comparing with previous studies, fatigue accumulation and significant influence in internal and external training load seem to be related to more than one stimulus strategy, the time of practice vs. rest interval time, pitch size and also GK participation. It was previously indicated that it is likely that SSGs are associated with the limitation of producing highspeed activities [41], because they are played on smaller pitch areas where the players do not have enough space to reach their maximal sprinting speed [42,43]. Our results support this hypothesis since the five performed SSGs were predominantly associated with distances covered at $0-6,6-12$ and $12-18 \mathrm{~km} \cdot \mathrm{h}^{-1}$ running speeds, when compared to $18-21 \mathrm{~km} \cdot \mathrm{h}^{-1}$, and fundamentally $21-24 \mathrm{~km} \cdot \mathrm{h}^{-1}$ and $24-50 \mathrm{~km} \cdot \mathrm{h}^{-1}$. The large number of significant changes throughout the SSGs in running speed, as well as distance covered and PL, were more evident when compared to HR, which means that external load changes differ comparatively to internal load in sub-elite soccer players. Our results revealed that the main factor for change in distance covered at different interval running speeds was the GK participation, namely in $6-12 \mathrm{~km} \cdot \mathrm{h}^{-1}$ and $12-18 \mathrm{~km} \cdot \mathrm{h}^{-1}$, since no significant changes were associated only to SSGs-P in different pitch dimensions, except with speed $12-18 \mathrm{~km} \cdot \mathrm{h}^{-1}$ and the increase in pitch size from SSG1 to SSG2 (respectively, $16 \times 24 \mathrm{~m}$ and $20 \times 30 \mathrm{~m}$ ). Interestingly, in $18-21 \mathrm{~km} \cdot \mathrm{h}^{-1}$ and $21-24 \mathrm{~km} \cdot \mathrm{h}^{-1}$, the SSG-P played in $24 \times 36 \mathrm{~m}$ without GK participation induced significantly higher running speeds compared to $16 \times 24 \mathrm{~m}$ and $20 \times 30 \mathrm{~m}$ pitch sizes, which supports the notion that small pitch sizes are a limitation for the occurrence of higher speeds. It is also noteworthy that distance covered tendentially decreased in every running speed interval with GK participation (except $0.6 \mathrm{~km} \cdot \mathrm{h}^{-1}$ ) and globally presenting the lower values in each running speed in SSG5 (also with the exception of $0.6 \mathrm{~km} \cdot \mathrm{h}^{-1}$ ), findings that highlight the need for a careful SSG training monitorization.

Some limitations should be considered when interpreting the findings of this study: (a) Participants were national and international-level male soccer players and played in teams with a specific playing system, which is related to the possibility that the results cannot be directly applied to other age categories and athletes of other levels and; (b) The research was conducted near the end of the competitive season (May); consequently, the protocol and results should not be applicable in other moments such as pre-season. Future studies could investigate SSGs constrains as for example the inclusion of more than two goals with and without goalkeepers, other pitch sizes, time of play and interval rest. It would also be interesting to analyze internal and external training load in other age-categories and in women's soccer, comparing with technical/tactical analysis. The GK evaluation should also be consider in future studies since it plays a key role in the soccer game.

\section{Conclusions}

This study suggests some practical implications for coaches, working with professional and sub-elite soccer players. Firstly, SSGs performed with professional and sub-elite soccer players composed by 3 min play and 3 min of interval rest periods represents an SSG 
training framework with relevant but steady state internal load fatigue and induce a considerable external load stimulus in pitch sizes between $16 \mathrm{~m}$ and $36 \mathrm{~m}$. Secondly, GK participation in SSGs should be carefully considered since it seems to have greater influence on the dynamics of the SSG compared to pitch size manipulation. Thirdly, our results recommend that smaller formats seem to promote higher exercise intensity but may be a limitation for the occurrence of higher running speeds, so it would be recommended to increase pitch size if coaches want to design tasks with greater focus on speed. These conclusions may contribute for soccer coaches' knowledge regarding the physical load measures during SSGs in sub-elite professional soccer players, which can result in the improvement of daily training workouts and, therefore, in players' and team's performance enhancement, since coaches play a key role in designing training sessions [44]. Finally, soccer coaches should consider that training monitorization as of crucial importance to understand the different internal and external load imposed in SSGs in sub-elite soccer players, which during periods of higher training and competitive load should be individually balanced. A detailed analysis of these soccer games is pivotal to an in-depth understanding of the workload imposed on each player aiming the prescription of an adequate type and amount of stimulus during soccer exercise training.

Author Contributions: Conceptualization, F.J.S. and M.C.E.; methodology, F.J.S., M.C.E. and C.C.F.; formal analysis, F.J.S., M.C.E. and T.P.F.; investigation, F.J.S., M.C.E., C.C.F. and T.P.F.; supervision, F.J.S. and M.C.E.; data curation, F.J.S. and M.C.E.; writing-original draft preparation, M.C.E., D.M.P.F., C.E.L.V., M.G.d.M., A.G.M. and R.P.B.; writing-review and editing, C.C.F., T.P.F., D.M.P.F, C.E.L.V., M.G.d.M., A.G.M. and R.P.B.; Visualization, F.J.S., M.C.E., D.M.P.F., C.E.L.V., M.G.d.M., A.G.M., T.P.F., C.C.F. and R.P.B.; funding acquisition, F.J.S., T.P.F., C.E.L.V. and M.G.d.M. All authors have read and agreed to the published version of the manuscript.

Funding: This research was funded by Foundation for Science and Technology, I.P., Grant/Award Number UIDB $/ 04748 / 2020$. T.P.F. acknowledges the financial support from Polytechnic Institute of Setúbal, and C.E.L.V. and M.G.d.M. the financial support from São Paulo State University (UNESP). A.G.M. acknowledges the fellowship from Coordenação de Aperfeiçoamento de Pessoal de Nível Superior-Brazil (CAPES-Finance Code 001).

Institutional Review Board Statement: The study was conducted according to the guidelines of the Declaration of Helsinki and submitted to the Ethical Committee of São Paulo State University (UNESP), which was registered and approved under (CAAE: 02523412.4.0000.5398, final report $n^{\circ}$ : 237.707).

Informed Consent Statement: Informed consent was obtained from all subjects, or their parents/guardians (when appropriate) involved in the study.

Data Availability Statement: The data that support the findings of this study are available from the corresponding and last authors (mario.espada@ese.ips.pt and fernando.santos@ese.ips.pt), upon reasonable request.

Acknowledgments: We would like to express our gratitude to the soccer players and coaches for their time and effort and the soccer team for making both their infrastructures and staff available for the study. The authors C.E.L.V., M.G.d.M and D.M.P.F. would like to thank PROPG-UNESP for the support from "Process 05/2021".

Conflicts of Interest: The authors declare no conflict of interest.

\section{References}

1. Bangsbo, J. The physiology of soccer: With special reference to intense intermittent exercise. Acta Physiol. Scand. 1994, 619, 1-155. [CrossRef]

2. Chamari, K.; Hachana, Y.; Kaouech, F.; Jeddi, R.; Moussa-Chamari, I.; Wisløff, U. Endurance training and testing with the ball in young elite soccer players. Br. J. Sports Med. 2005, 39, 24-28. [CrossRef]

3. Iaia, M.F.; Rampinini, E.; Bangsbo, J. High-intensity training in football. Int. J. Sports Physiol. Perform. 2009, 4, 291-306. [CrossRef] [PubMed]

4. Aurélio, J.; Dias, E.; Soares, T.; Espada, M.; Jorge, G.; Pessôa Filho, D.; Pereira, A.; Figueiredo, T. Relationship between body composition, anthropometry and physical fitness in under-12 soccer players of different positions. Int. J. Sports Sci. 2016, 6, 25-30. [CrossRef] 
5. Hammami, A.; Gabbett, T.J.; Slimani, M.; Bouhlel, E. Does small-sided games training improve physical fitness and teamsport-specific skills? A systematic review and meta-analysis. J. Sports Med. Phys. Fitness. 2018, 58, 1446-1455. [CrossRef] [PubMed]

6. Clemente, F.M. Small-Sided and Conditioned Games in Soccer Training: The Science and Practical Applications; Springer: Singapore, 2016 ; p. 6.

7. Espada, M.; Fernandes, C.; Martins, C.; Leitão, H.; Figueiredo, T.; Santos, F. Goal characterization after ball recovery in players of both genders of first league soccer teams in Portugal. Hum. Mov. 2018, 19, 73-81. [CrossRef]

8. Dellal, A.; Owen, A.; Wong, D.P.; Krustrup, P.; van Exsel, M.; Mallo, J. Technical and physical demands of small vs. large sided games in relation to playing position in elite soccer. Hum. Mov. Sci. 2012, 31, 957-969. [CrossRef]

9. Milanović, Z.; Pantelić, S.; Čović, N.; Sporiš, G.; Mohr, M.; Krustrup, P. Broad-spectrum physical fitness benefits of recreational football: A systematic review and meta-analysis. Br. J. Sports Med. 2019, 53, 926-939. [CrossRef]

10. Espada, M.; Figueiredo, T.; Ferreira, C.; Santos, F. Body composition and physical Fitness Analysis in Different Field Position U-15 Soccer Players. J. Phys. Educ. Sport. 2020, 20, 1917-1924. [CrossRef]

11. Halouani, J.; Chtourou, H.; Gabbett, T.; Chaouachi, A.; Chamari, K. Small-sided games in team sports training: A brief review. J. Strength Cond. Res. 2014, 28, 3594-3618. [CrossRef] [PubMed]

12. Casamichana, D.; Castellano, J. The relationship between intensity indicators in small-sided soccer games. J. Hum. Kinet. 2015, 45, 119-128. [CrossRef]

13. Kelly, D.M.; Drust, B. The effect of pitch dimensions on heart rate responses and technical demands of small-sided soccer games in elite players. J. Sci. Med. Sport. 2009, 12, 475-479. [CrossRef]

14. Sassi, R.; Reilly, T.; Impellizzeri, F.A. Comparison of small-sided games and interval training in elite professional soccer players. J. Sports Sci. 2004, 22, 352-354. [CrossRef]

15. Fanchini, M.; Azzalin, A.; Castagna, C.; Schena, F.; McCall, A.; Impellizzeri, F.M. Effect of bout duration on exercise intensity and technical performance of small-sided games in soccer. J. Strength Cond. Res. 2011, 25, 453-458. [CrossRef] [PubMed]

16. Köklü, Y.; Alemdaroğlu, U.; Cihan, H.; Wong, D.P. Effects of bout duration on players' internal and external loads during small-sided games in young soccer players. Int. J. Sports Physiol. Perform. 2017, 12, 1370-1377. [CrossRef] [PubMed]

17. Halouani, J.; Chtourou, H.; Dellal, A.; Chaouachi, A.; Chamari, K. The effects of game types on intensity of small-sided games among pre-adolescent youth football players. Biol. Sport. 2017, 34, 157-162. [CrossRef] [PubMed]

18. Halouani, J.; Chtourou, H.; Dellal, A.; Chaouachi, A.; Chamari, K. Soccer small-sided games in young players: Rule modification to induce higher physiological responses. Biol. Sport. 2017, 34, 163-168. [CrossRef] [PubMed]

19. Clemente, F.; Nikolaidis, P.; Linden, C.; Silva, B. Effects of small-sided soccer games on internal and external load and lower limb power: A pilot study in collegiate players. Hum. Mov. 2017, 18, 50-57. [CrossRef]

20. Selmi, O.; Haddad, M.; Majed, L.; Ben Khalifa, W.; Hamza, M.; Chamari, K. Soccer training: High-intensity interval training is mood disturbing while small sided games ensure mood balance. J. Sports Med. Phys. Fit. 2018, 58, 1163-1170. [CrossRef] [PubMed]

21. Harriss, D.J.; MacSween, A.; Atkinson, G. Ethical Standards in Sport and Exercise Science Research: 2020 Update. Int. J. Sports Med. 2019, 40, 813-817. [CrossRef] [PubMed]

22. Santos, F.J.L.; dos Louro, H.G.; Espada, M.; Figueiredo, T.; Lopes, H.; Rodrigues, J. Relation of coaches' expectations with instruction and behavior of athletes. Cuad. Psicol. Deporte. 2019, 19, 62-78. [CrossRef]

23. Bastida-Castillo, A.; Gomez-Carmona, C.D.; De La Cruz Sanchez, E.; Pino-Ortega, J. Comparing accuracy between global positioning systems and ultra-wideband-based position tracking systems used for tactical analyses in soccer. Eur. J. Sport Sci. 2019, 19, 1157-1165. [CrossRef]

24. Levine, T.R.; Hullett, C.R. Eta squared, partial eta squared, and misreporting of effect size in communication research. Hum. Commun. Res. 2002, 28, 612-625. [CrossRef]

25. Cohen, J. Statistical Power Analysis for the Behavioral Sciences, 2nd ed.; Lawrence Erlbaum Associates: Hillsdale, NJ, USA, 1988.

26. Castillo, D.; Rodriguez-Fernandez, A.; Nakamura, F.Y.; Sanchez-Sanchez, J.; Ramirez-Campillo, R.; Yanci, J.; Zubillaga, A.; RayaGonzález, J. Influence of different small-sided game formats on physical and physiological demands and physical performance in young soccer players. J. Strength Cond Res. 2019, 1, 1-7. [CrossRef]

27. Impellizzeri, F.M.; Marcora, S.; Castagna, C.; Reilly, T.; Sassi, A.; Iaia, F.M.; Rampinini, E. Physiological and performance effects of generic versus specific aerobic training in soccer players. Int. J. Sports Med. 2006, 27, 483-492. [CrossRef]

28. Rampinini, E.; Impellizzeri, F.; Castagna, C. Factors influencing physiological responses to small-sided soccer games. J. Sports Sci. 2007, 25, 659-666. [CrossRef]

29. Little, T.; Williams, A.G. Measures of exercise intensity during soccer training drills with professional soccer players. J. Strength Cond. Res. 2007, 21, 367-371. [CrossRef]

30. Pantelić, S.; Rađa, A.; Erceg, M.; Milanović, Z.; Trajković, N.; Stojanović, E.; Krustrup, P.; Randers, M.B. Relative pitch area plays an important role in movement pattern and intensity in recreational male football. Biol. Sports 2019, 36, 119-124. [CrossRef] [PubMed]

31. Köklü, Y.; Ersöz, G.; Alemdaroglu, U.; Aşç, A.; Ozkan, A. Physiological responses and time motion characteristics of 4-a-side small-sided game in young soccer players: The influence of different team formation methods. J. Strength Cond. Res. 2012, 26, 3118-3123. [CrossRef] 
32. Gaudino, A.G.; Iaia, F.M. Estimated metabolic and mechanical demands during different small-sided games in elite soccer players. Hum. Mov. Sci. 2014, 36, 123-133. [CrossRef] [PubMed]

33. Owen, A.L.; Wong, D.P.; Paul, D.; Dellal, A. Physical and technical comparisons between various-sided games within professional soccer. Int. J. Sports Med. 2014, 35, 286-292. [CrossRef]

34. Brisswalter, J.; Collardeau, M.; René, A. Effects of acute physical exercise characteristics on cognitive performance. Sports Med. 2002, 32, 555-566. [CrossRef] [PubMed]

35. Randers, M.B.; Orntoft, C.; Hagman, M.; Nielsen, J.J.; Krustrup, P. Movement pattern and physiological response in recreational small-sided football-Effect of number of players with a fixed pitch size. J. Sports Sci. 2018, 36, 1549-1556. [CrossRef]

36. Brink, M.S.; Visscher, C.; Arends, S.; Zwerver, J.; Post, W.J.; Lemmink, K.A. Monitoring stress and recovery: New insights for the prevention of injuries and illnesses in elite youth soccer players. Br. J. Sports Med. 2010, 44, 809-815. [CrossRef]

37. Clemente, F.M.; Martins, F.M.; Mendes, R.S. Developing aerobic and anaerobic fitness using small-sided soccer games: Methodological proposals. Strength Cond. J. 2014, 36, 76-87. [CrossRef]

38. Silva, B.; Garganta, J.; Santos, R.; Teoldo, I. Comparing Tactical Behaviour of Soccer Players in 3 vs. 3 and 6 vs. 6 Small-Sided Games. J. Hum. Kinet. 2014, 41, 191-202. [CrossRef]

39. Casamichana, D.; Castellano, J.; Dellal, A. Influence of different training regimes on physical and physiological demands during small-sided soccer games. J. Strength Cond. Res. 2013, 27, 690-697. [CrossRef] [PubMed]

40. Dellal, A.; Lago-Penas, C.; del Wong, P.; Chamari, K. Effect of the number of ball contacts within bouts of 4 vs. 4 small-sided soccer games. Int. J. Sports Physiol. Perform. 2011, 6, 322-333. [CrossRef]

41. Casamichana, D.; Castellano, J.; Castagna, C. Comparing the physical demands of friendly matches and small-sided games in semi-professional soccer players. J. Strength Cond. Res. 2012, 26, 837-843. [CrossRef]

42. Buchheit, M.; Al Haddad, H.; Simpson, B.M.; Palazzi, D.; Bourdon, P.C.; Di Salvo, V.; Mendez-Villanueva, A. Monitoring accelerations with GPS in football: Time to slow down? Int. J. Sports Physiol. Perform. 2014, 9, 442-445. [CrossRef]

43. Santos, F.J.; Ferreira, C.M.; Figueiredo, T.P.; Espada, M.C. Influence of different 1v1 small-sided game conditions in internal and external load of U-15 and U-12 soccer players. TRENDS Sport Sci. 2021, 29, 45-53. [CrossRef]

44. Rodrigues, J.; Rodrigues, F.; Resende, R.; Espada, M.; Santos, F. Mixed Method Research on Football Coaches' Competitive Behavior. Front. Psychol. 2021, 13, 705557. [CrossRef] [PubMed] 